\title{
Los fondos de inversión en el fútbol. Algunos problemas éticos y jurídicos
}

\author{
Investment funds in football. Some ethical and legal \\ problems
}

\author{
JOSÉ LUIS PÉREZ TRIVIÑO*Y EVA CAÑIZARES RIVAS** \\ * Universidad Pompeu Fabra de Barcelona (España). ${ }^{* *}$ Centro Deportivo Fundición, Consultoría y Asesoría \\ JuRídico-DePortiva (EsPAÑa).
}

Artículo recibido: 29 agosto 2015

Solicitud de revisión: 1 octubre 2015

Artículo aceptado: 04 enero 2016

Resumen

Los fondos de inversión se han convertido en los últimos años en un mecanismo frecuente que los clubes de fútbol utilizan para financiar el fichaje de jugadores. Aunque muchos autores han destacado sus efectos beneficiosos al permitir que los clubes adquieran jugadores que de otra manera no podrían conseguir, en este trabajo nos centramos en enfatizar dos problemas que pueden plantear. En primer lugar, hemos tratado de mostrar que pueden generar un progresivo alejamiento de los aficionados. En segundo lugar, a través del dilema del prisionero nos hemos propuesto mostrar que pueden contribuir a aumentar a largo plazo la deuda de los clubes y amenazar el fair play financiero.

Palabras clave: fondos de inversión, fair play, financiero, dilema del prisionero

\begin{abstract}
Investment funds have become in recent years a frequent mechanism football clubs use to finance signing of football players.Although many authors have highlighted their beneficial effects by allowing clubs to acquire players who otherwise they would not get, in this paper we focus on two problems. First, we have tried to show that they can generate a progressive distancing from the fans. Secondly, through the prisoner's dilemma we intend to show that they can contribute to increasing long-term clubs debt and threaten the financial fair play.
\end{abstract}

Keywords: investment funds, fair play, financial, prisoners' dilemma

\section{INTRODUCCIÓN}

El deporte hace tiempo que dejó de ser una simple manifestación social, vinculada al entretenimiento o satisfacción personal, para ser considerado 
como un bien, cuya producción, consumo, financiación y gestión responde a criterios de racionalidad económica (Avezuela, 2015). El proceso de progresiva mercantilización del fútbol es incuestionable y tiene en el ámbito español a la Ley 10/1990, de 15 de octubre, del Deporte como un referente legal al establecer medidas para racionalizar la faceta empresarial de los clubes.

Ahora bien esa conversión hacia la mercantilización de los clubes de fútbol en la que ha destacado el énfasis en la racionalización y eficiencia de la gestión económica no ha sido pacífica, pues como se señalará más adelante no ha alcanzado todos los objetivos que se pretendían. Como señalaremos posteriormente los propósitos de racionalización en la gestión no se han logrado en su totalidad. Por otro lado, esa lógica mercantilista en la actividad empresarial de los clubes de fútbol tiene en la actualidad como una de sus ramificaciones la intervención de los fondos de inversión, los cuales provocan la cuestión de si suponen una amenaza o una solución a los clubes de fútbol y a la competición como tal está establecida. La mecánica de los fondos de inversión en cuanto que inversores en derechos económicos de los futbolistas, también conocidos por las siglas TPO (del inglés Third Party Ownership), es sencilla y, básicamente, puede definirse como la compra por parte de inversores de los derechos económicos de un jugador con el objetivo de ingresar la plusvalía generada en futuros traspasos. ${ }^{1}$ Debido a la crisis económica, muchos clubes han recurrido a la utilización de esta herramienta de financiación como única forma de afrontar operaciones de fichajes en un momento en que han visto cerradas todas las puertas de acceso al crédito bancario. Esta ha sido una práctica muy habitual en Argentina y Brasil donde el 90\% de los futbolistas de Primera División pertenecen a FI. Un ejemplo por todos conocidos es el futbolista Neymar, que cuando lo fichó el Fútbol Club Barcelona (FCB) tenía vendidos el 40\% de sus derechos económicos a DIS y el 5\% a TIESA. En Europa no ha sido tan habitual recurrir a los FI como en Sudamérica, situándose el volumen en manos de inversores, según datos de la consultora KPMG, en torno al 40\% en los países del Este de Europa, el 36\% en Portugal y el 7\% en nuestro país. Solo Francia, Reino Unido y Polonia habían prohibido los fi antes de que lo hiciera la FIFA.

En la medida que la actividad de los Fondos de Inversión (FI) ${ }^{2}$ agravan esa oposición con otros valores del fútbol (la integridad deportiva) o los de-

1 Hay otras modalidades de intervención de los TPO, pero no las analizaremos aquí. Véase Cazorla.

2 Hay diversos tipos de Fi (TPo de financiación, de inversión o de formación o captación de jugadores), pero nuestra atención se limitará en los que tienen que ver con la adquisición de derechos económicos sobre un jugador (тРо de inversión): Incluyen «el conjunto de operaciones de financiación, generalmente a clubes de fútbol pero en ocasiones también a los propios futbolistas, en las que la finan- 
rechos laborales de los trabajadores, están siendo puestos en cuestión. Pero en este trabajo nos centraremos en dos riesgos que han recibido menos atención: la pérdida de la lealtad de los aficionados y el que los fi puedan ir, paradójicamente, en contra de los propios intereses económicos de los clubes.

\section{LOS FONDOS DE INVERSIÓN Y LA PERSPECTIVA DEL AFICIONADO}

Un aspecto apenas mencionado en el análisis del impacto de los FI sobre el fútbol es el que tiene que ver con los aficionados. Suele escaparse a la comprensión de lo que es el fenómeno deportivo y en particular del futbolístico, el impacto que este tiene sobre los colectivos humanos que sienten un especial lazo emocional con un club. Durante mucho tiempo la existencia y persistencia de los clubes pivotaba principalmente sobre el apoyo no solo emocional sino económico que prestaban sus seguidores. Antes de convertirse en las máquinas empresariales que son hoy, los clubes eran asociaciones privadas respaldadas por sus aficionados. Los presupuestos económicos se dimensionaban sobre la capacidad de los estadios y estos, a su vez, sobre el número de aficionados que estaban dispuestos a hacerse socios del club o asistir a los partidos y pagar la correspondiente entrada.

Un segundo aspecto de la relación entre los clubes deportivos y los aficionados es que aquellos han sido históricamente fuente de identidad para la ciudadanía. Como señala M. Sandel

«los estadios deportivos son las auténticas catedrales de nuestra religión civil, espacios públicos que congregan a personas de diferentes clases y orígenes en un ritual de derrotas y esperanzas, de blasfemias y oración» (Sandel, 119).

Con más o menos intensidad esta inquebrantable devoción cívica es una regla en el mundo del fútbol donde los clubes son constitutivamente entidades emocionales que una vez atrapan a sus seguidores, estos ya no cambian de lealtad. ${ }^{3}$ Pocos sentimientos se labran tan pronto en un aficio-

ciación concedida, cualquier que sea el sujeto que la conceda (fondos, sociedades, agentes/ representantes de jugadores, bancos o cualquier tercero distinto de un club de fútbol), tiene como contraprestación o garantía, los derechos económicos derivados de los federativos de un jugador de fútbol» (Cazorla, 44-45).

3 Este rasgo constituye un elemento diferenciador crucial respecto del mundo empresarial. Por eso, en parte, muchos empresarios a la par que se sienten atraídos por entrar en el mundo del fútbol, fracasan en su gestión al tratar de aplicar criterios económicos y de gestión propios de las empresas a los clubes futbolísticos. La preocupación de los presidentes y las juntas directivas deja de ser principal- 
nado y duran tanto y tan profundamente como los ligados a la fidelidad hacia un club. Son extraños los ejemplos de un aficionado que cambie de colores. Los avatares del equipo no suelen perturbar su fidelidad. Incluso cuando los resultados no acompañan y se desciende de categoría, se da en ocasiones la circunstancia de que aumenta el número de socios. ${ }^{4}$

Un tercer factor vinculado a esa tradicional vinculación histórica entre clubes y aficionados también ha sido destacado por Sandel: lo que el seguidor de un club experimentaba cuando acude al estadio a ver un partido son dos elementos relevantes de la vida pública democrática: la igualdad básica entre ciudadanos y el sentimiento de pertenencia a un lugar específico. De forma perspicaz, Sandel describe este efecto colateral del fenómeno deportivo de la siguiente manera:

«Es cierto que los palcos de tribuna siempre han costado más que las entradas de general, pero los estadios deportivos son uno de los pocos espacios públicos donde los directores generales de las empresas se sientan al lado de los repartidores de correos y donde todos comen los mismos perros calientes grasientos, donde ricos y pobres se mojan si llueve, donde todos los corazones se encogen o estallan al unísono, según la suerte del equipo local. O al menos así era hasta hace poco» (Sandel, 120).

Sin embargo, esta situación de preeminencia de los aficionados como soporte económico de los clubes hace tiempo que desapareció. La conversión de los clubes en sociedades anónimas ha conducido que los clubes desarrollen su actividad como verdaderas empresas, obteniendo sus principales ingresos de la venta de derechos de retransmisión televisiva, venta de camisetas y merchandising en general. Como señala Diego Molina, esta transformación convierte a los aficionados en clientes, de forma que «la relación entre ambos es sencillamente la que existe entre el prestador de un servicio y el consumidor del mismo, con todos los componentes jurídicos y económicos propios de tal relación bilateral».

mente la gestión deportiva para empezar a serlo el aumento de los beneficios por la venta de derechos de imagen y de retransmisión televisiva (y para ello no dudan en modificar los horarios tradicionales de los partidos) o vender más camisetas (con publicidad, por supuesto) en una zona determinada del globo terráqueo, para lo cual planean fichajes estratégicos o estancias de pretemporada que más parecen pensadas para enseñar el «mostruario» de estrellas que forman parte de la plantilla. Cuando faltan títulos, se alardea del presupuesto que se maneja: cuanto mayor, mejor. No afirmamos que esto sea el único objetivo en la gestión, también lo sigue siendo conseguir victorias y títulos. Pero da la impresión que los títulos sean un medio para vender más camisetas y para ello se aprovechan de la fidelidad de sus aficionados. El resultado al que se puede llegar con este proceso es a la tergiversación más absoluta de la finalidad originaria de los clubes de fútbol: de estandarte de emociones grupales a empresas con intereses económicos.

4 El lema del Betis es quizá un perfecto reflejo de esta actitud: «Viva el Betis manque pierda». 
En concordancia con este proceso, aquellas virtudes democráticas anejas al fenómeno deportivo también corren el riesgo de desaparecer a la par que los administradores rigen el club con criterios puramente empresariales. Así Sandel apunta que como ejemplo de estas medidas, «la proliferación de palcos de lujo segrega a una reducida élite de la plebe que se sienta en las gradas inferiores» (Sandel, 120). Es decir, que tales decisiones que afectan al diseño de los estadios en aras a obtener mayores ingresos amenazan con liquidar ese rasgo igualitarista que se vivía en los estadios de antaño. ${ }^{5}$

Pues bien, la proliferación de los fi también constituyen un riesgo de acentuar la caída por dicha pendiente de desvinculación emocional del aficionado respecto del club. No es fácil determinar de manera precisa el conjunto de factores que empujan a que un aficionado se vincule a un club, ${ }^{6}$ como tampoco los elementos que delimitan la identidad de un club. Pero sin duda, en una aproximación rápida diríamos que juegan un papel central una historia compartida, una camiseta, un escudo, pero también una narrativa coherente en el tiempo. En dicha narración desempeñan un papel fundamental el club (presidente y junta directiva, entrenadores, etc) y los jugadores, como dos actores que agotaban el universo de la descripción de lo que es el objeto de lealtad por parte de los aficionados. Poca duda había hasta el momento, salvo excepciones contadas, acerca de la pertenencia de un jugador a un club. Club a su vez, suele tener una vinculación fuerte con una determinada ciudad o territorio, a la que de alguna manera, servía de representación.

Sin embargo, la aparición de los fi destruye ese entramado de relaciones coherentes entre club, jugadores y aficionados. En la medida que un FI (o varios) puede poseer los derechos económicos de uno o varios jugadores

5 Desde la reforma supuso una transformación radical de la forma jurídica de relacionarse los aficionados con los clubes. Mientras estos mantienen la naturaleza de asociaciones civiles, los aficionados tienen la posibilidad jurídica de ser parte integrante de los mismos en condiciones de igualdad con los demás miembros; sin embargo, al producirse la transformación en sociedad anónima los socios del club son despojados de su derecho a formar parte de la entidad y se convierten en otra cosa diferente y externa a ella. El club transformado en SAD pasa de ser una entidad compuesta de personas que se agrupan en torno a un fin común a convertirse en una entidad compuesta de capital, que es una «cosa», un valor de naturaleza económica susceptible de tener uno o varios dueños que pueden, además, comerciar con él.

6 Diego Molina señala al respecto: «En realidad, los factores que motivan a los aficionados a agruparse emocionalmente en torno a un club de fútbol carecen, en la práctica totalidad de los casos, de contenido mercantil alguno y tienen que ver más bien, como apuntamos anteriormente, con señas de identidad geográfica o territorial, de pertenencia a un determinado grupo social, cultural o político o incluso con la encarnación de determinados valores de tipo ético o moral -la lucha del débil frente al poderoso, el sacrificio, el pundonor, etc.-. En todos los casos se trata de elementos inmateriales que los aficionados "sienten" que son representados por el club -aunque en no pocas ocasiones ni siquiera sean fomentados por este-, pero que no forman parte, en sentido económico o jurídico, del patrimonio de la entidad». 
de un mismo club, no sabemos muy bien, por quién y para quién juega el futbolista.También se rompe la vinculación entre aficionado, club y territorio, en tanto que los fi son entidades ubicuas carentes de arraigo territorial, histórico y anímico con el club. Pero quizá lo más grave es que puede llegar a romperse la vinculación entre los aficionados con el club y con los futbolistas. Y si esto llega a ocurrir las probabilidades de que los aficionados se desvinculen del club son altas. ${ }^{7} \mathrm{Y}$ si esto ocurre, la propia pervivencia del club estaría amenazada. Como señala Diego Molina: «resulta muy difícil o casi imposible encontrar un ejemplo de algún club que [...] haya logrado subsistir cuando se extingue el nexo de unión con el "sentimiento" de los aficionados, bien sea por la propia voluntad de estos, que dejen de sentirse "representados" por la entidad, o bien sea por la decisión del propio club de desarraigarse de su masa social afectiva».

\section{LOS FI, FICHAJES Y CARRERA ARMAMENTÍSTICA EN EL ENDEUDAMIENTO}

Uno de los principales argumentos a favor de los fi es que constituyen una herramienta adecuada para paliar las necesidades financieras de los clubes o la pretensión de fichar jugadores que de otra manera no podrían conseguir. Como rasgo general, la defensa de este instrumento financiero suele ponerse en relación con las bondades de la gestión privada y profesionalizada de los clubes que se puso en marcha con la Ley del Deporte de 1990 y con la obligatoria conversión de la mayor parte de los clubes de primera y segunda división en sociedades anónimas deportivas. Una segunda bondad de los fi es que permiten conseguir a los clubes éxitos deportivos que de otra manera no podrían alcanzar. Veamos con más detalles ambos argumentos.

La gestión económica profesionalizada en el fútbol español remite necesariamente a la década de los años 80 del pasado siglo, donde la situación de los clubes en esas fechas era en general desesperada dadas las enormes y acuciantes deudas que habían contraído. Suele ser habitual entre algunos autores atribuir tal ineficiencia al carácter «específico» del deporte y en especial, del fútbol y su «función social».Así L. Cazorla señala: «durante años y

7 Como señala V. Rodrigo: «El 'alma' y tradición histórica de los clubs, la devoción y pasión de los aficionados por los colores de su equipo, son los principales activos del fútbol; UEFA, consciente de ello, pretende que los clubs sean independientes a los ingresos provenientes del «mecenazgo» y los «sugar daddies», habida cuenta de la naturaleza volátil de los mismos, generadores de distorsiones contraproducentes para la estabilidad del negocio del fútbol» (Rodrigo, 3). 
décadas, al abrigo de su mal entendida 'función social' y del apoyo brindado por el Poder Público, se ha mantenido al margen de cualquier lógica de eficiencia y racionalidad, impulsándose, de este modo, una burbuja artificial» (Cazorla, 40). El plan de saneamiento ${ }^{8}$ que se estableció y que incluía la conversión obligatoria de la mayoría de clubes en sociedades anónimas parecía que daría respuesta a los objetivos pretendidos (Avezuela, 136), sobre todo al vincularse el gobierno de las nuevas SAD a una gestión profesionalizada (Cazorla, 40).

Sin embargo, esos objetivos distan mucho de haberse cumplido, siendo el endeudamiento de los clubes en la actualidad de más de 3000 millones de euros. Es precisamente esta situación económica la que dificulta el acceso por parte de los clubes a fuentes de financiación tradicionales y si a ello juntamos la retirada de las ayudas (y privilegios) por parte de los poderes públicos encontramos las circunstancias que algunos expertos alegan para justificar la intervención de los fondos de inversión en el fútbol profesional español. ${ }^{9}$

Como ya se ha dicho en repetidas ocasiones por los defensores de este instrumento financiero, gracias a los FI, los clubes consiguen aquellos fines económicos y deportivos que de otra manera no podrían alcanzar. Así por ejemplo, los dirigentes del Atlético de Madrid han manifestado respecto a la virtualidad «deportiva» de los fi que sin ellos, su club no hubiera logrado los éxitos que han logrado en los últimos años. Según Gil Marín: «La figura del TPO nos ha servido para poner el equipo a competir»; es más, «...hemos duplicado los ingresos, hemos jugado diez finales y ganado siete títulos». ${ }^{10}$

Sin embargo en este inventario de argumentos favorables a la intervención de los fi hay varias objeciones que es preciso tomar en consideración. En primer lugar, la supuesta ventaja de la conversión de los clubes en SAD (y con ello, la supuesta profesionalización de la gestión económica) es más que dudosa.

En segundo lugar, a pesar de las pretendidas ventajas que para los clubes tienen el recurso a los Fi para contratar jugadores, esto puede llevar un endeudamiento futuro inasumible por el propio club.

8 Como es sabido la Ley del Deporte de 1990 fue modificada por la Ley 50/1999 que debilitaba el control que inicialmente preveía la Ley del Deporte (Otero Lastres, p. 828).

9 Así Avezuela señala: «La participación de instrumentos de financiación que son propios en cualquier otro sector económico como los fondos de inversión siempre que fuera debidamente regulada y sometida a los correspondientes controles... podría derivar no solo en una solución a los aspectos puramente financieros (Avezuela, p. 137)

10 http://www.marca.com/2015/04/09/futbol/equipos/atletico/1428584705.html Última visita: $11 / 6 / 2015$ 
En tercer lugar, puede ser contrario a sus intereses de contar con el jugador a largo plazo, ya que el fi puede influir para vender rápidamente al jugador.

En cuarto lugar, la lógica deportiva de perseguir la victoria a toda costa pervierte la gestión financiera de los clubes conduciendo a una situación de dilema del prisionero, y con ello, a un endeudamiento galopante que no solo podría perjudicar a la mayoría de los clubes sino que también es contrario a medidas como el Fair Play Financiero.

Respecto a la primera crítica, cabe decir que veinte años después de la conversión de los clubes en SAD, se vuelve a repetir el «descalabro» económico con muchos clubes en una situación financiera muy delicada. Los datos globales del endeudamiento no dejan margen a la duda: en 2010, las deudas de los clubes de primera y segunda división de fútbol era de 3.526 millones de euros, cuando en 1990 era de 210 millones, lo que supone un incremento de, nada menos, el 1.700 por ciento, en términos porcentuales. ${ }^{11}$ La cuestión que se plantea inmediatamente es cuáles son las causas principales de tal debacle económica ¿la especificidad del deporte? ¿su función social? ¿la gestión pública? Parece que no. Según Otero Lastres (p. 831), las causas del fracaso en la gestión económica de los clubes han sido: 1) la falta de profesionalidad y rigor con que se han gestionado las SAD; 2) el fallo de los sistemas de autocontrol, entre otros de la LFP integrada por los propios clubes de fútbol, y 3) la laxitud con la que han actuado los propios acreedores de la deuda ante la fuerza social de los clubes (Otero Lastres, p.819). Aquí habría que apuntar a la excesiva permisividad de las administraciones públicas con las deudas tributarias y las de Seguridad Social (Cazorla, 41).

En segundo lugar, si analizáramos los efectos de los fi sobre un club particular el resultado podría ser inicialmente y en ciertas ocasiones positivo: tanto a nivel económico como deportivo. Así podrían acceder a una fuente de financiación que puede repercutir en el logro de éxitos deportivos. Recordemos en este sentido las palabras de Gil Marín en defensa de los FI, gracias a los cuales habría logrado varios títulos nacionales e internacionales. Sin embargo, no todo son juicios positivos. La UEFA ha recordado que pueden darse efectos perjudiciales: la posible afectación a los clubes que utilizan los fi comprometiéndose económicamente a obligaciones que no puedan asumir en un momento posterior.Y es que la tentación de acudir a

11 Estos datos llevaron a la LFP a adoptar un Reglamento de Control Económico que ha entrado en vigor esta temporada 2014-15 con el objetivo de promover la solvencia de los clubes, estableciéndose la obligación para los clubes de presentar estados financieros auditados, y prohibiéndose que su deuda supere el $100 \%$ de los fondos propios y que los gastos relativos al pago de ficha de jugadores y cuerpo técnico no supere el $70 \%$ de los mismos (De Dompablo, p. 113). 
la FI es grande cuando los bancos (entidades por lo general más cuidadosas con sus inversiones) suelen poner más dificultades a la concesión de los créditos que les solicitan. ${ }^{12} \mathrm{~A}$ esto hay que sumar otro riesgo: los fi no son precisamente $\mathrm{ONG}$, sino entidades muy preocupadas por generar beneficios a sus partícipes por lo que centran su inversión en entidades que les ofrezcan perspectivas de crecimiento y expansión sólidas, por lo que en el mundo del fútbol sus inversiones pueden contribuir a aumentar todavía más las desigualdades ya existentes.

En tercer lugar, el beneficio de fichar a un jugador a través de los Fi puede no ser duradero, dado el interés de los FI en «mover» a sus jugadores a través de traspasos. Sin los traspasos los fi no tienen razón de existir ya que por naturaleza son cortoplacistas (De Dompablo, 110): sus expectativas de beneficios están en los movimientos de las fichas federativas de los jugadores. Va de suyo que esto no solo afecta a la evolución de la propia carrera profesional del futbolista, sino al club que cede los derechos económicos, pues su esfuerzo por adquirir los derechos del jugador y disfrutar de su rendimiento deportivo durante varias temporadas puede verse frustrado si el FI «presiona» para un traspaso rápido. Es decir, se produciría un conflicto entre el interés deportivo del club y el económico del FI, ${ }^{13}$ amenaza que trataba de ser conjurado con el artículo 18bis del RETJ.

En cuarto lugar, y este es el punto al que queremos dedicar más atención, la doble naturaleza de los clubes que son, por un lado, entes económicos y por otro lado, entidades deportivas, no es en absoluta pacífica. Los clubes se rigen por lógicas no solo distintas, sino que en determinadas circunstancias pueden ser contradictorias (Otero Lastres, 830). Para decirlo en términos de teoría de juegos, la lógica económica donde se desarrolla la actividad de las empresas es en muchos casos del tipo ganar-ganar (win-win) en la que todos obtienen resultados provechosos si es el caso de que el esquema donde se desarrolla la actividad está bien diseñado para que todos puedan beneficiarse de una u otra manera, ocurriendo esto precisamente por la intervención de límites externos al propio mercado. Dicho rápidamente, en la lógica del mercado ideal es generalmente beneficioso que haya competidores. Pero el valor de la competencia no siempre está garantizado por la lógica de aquel, ya que puede ser autodestructivo con el surgimiento de monopolios u oligopolios. Precisamente ese valor se salvaguarda con

12 Como desarrolla De Dompablo la inversión en el actual mundo del fútbol profesional no es fácil para los eventuales inversores (De Dompablo, 110).

13 Véase el conflicto entre Doyen Sports (TPO) y el Sporting Club de Portugal con relación al jugador Marcos Rojo. Cazorla, L. (2014). «El conflicto Doyen-Sporting de Lisboa y la seguridad jurídica«, Iusport. http://iusport.com/not/2753/el-conflicto-doyen-sporting-de-lisboa-y-la-seguridad-juridica/ 
normas sancionatorias externas al propio mercado que tratan de garantizar esa pluralidad de agentes económicos, los cuales pueden permanecer en el mercado obteniendo beneficios (aunque este no sea necesariamente el mismo).

En cambio la lógica de la competición deportiva es un juego de suma cero, es decir, un esquema donde uno de los jugadores lo gana todo y el otro, todo lo pierde. En cambio, la lógica deportiva conduce necesariamente a que, en general, solo haya un ganador. El resto, incluido el segundo, es un perdedor. Y es que para caracterizarlo en términos económicos, la victoria en un contexto deportivo es un «bien posicional», aquel cuyo valor está clasificado en función del atractivo que genera a otros agentes.Así por ejemplo, la fama o la obtención de una reserva en un restaurante de moda no pueden repartirse igualitariamente: solo unas pocas personas pueden ser famosas o solo puede haber un restaurante de moda. La medida de la satisfacción derivada de una buena posición depende de cuánto uno tiene en relación con los demás. Dado que los bienes posicionales son escasos tienen una naturaleza selectiva. Y su consecución es un claro ejemplo de juego de suma cero. Y así son las victorias deportivas, bienes escasos y posicionales.

La cuestión relevante en este caso es que la lógica deportiva contamina a la económica y arrastra a los gestores económicos, incluso a los más racionales y profesionales, a una situación de dilema del prisionero en la que todos salen perdiendo, ya que se ven arrastrados a una dinámica perversa en la que todos se ven forzados a invertir en mejores jugadores para tratar de obtener la victoria.

Dadas las similitudes entre el fútbol y una batalla militar, no parece desafortunado utilizar aquí el símil de la carrera armamentística. Veamos cómo se produce esta en el esquema del dilema del prisionero: imaginemos dos equipos de fútbol de nivel deportivo y económico más o menos similar. Ambos están interesados en ganar el campeonato, lo cual significa derrotar a los rivales. Para ello cuentan como fuente para mejorar su rendimiento deportivo el fichar a jugadores externos. Pero a la vez, ambos clubes son conscientes de que el gasto que pueden hacer en esos fichajes no es ilimitado. Un gasto excesivo (acompañado de un deficiente rendimiento del jugador, dada la incertidumbre que caracteriza a este activo) puede llevar a una merma del potencial económico del club y a larga no solo perder oportunidades competitivas sino incluso, desaparecer si las deudas se disparan. En este escenario, ambos clubes son conscientes de que se encuentran en una situación de interdependencia estratégica en el sentido de que 
sus (mejores) decisiones no son unilaterales sino que dependen de lo que haga el rival, con el que, por cierto, no pueden establecer comunicación para una eventual negociación (y aunque la establecieran siempre estaría la amenaza de la traición).

En esta situación, se plantean varias alternativas. En la primera, ambos clubes deciden cooperar, en el sentido de que ninguno decide emprender fichajes caros. En este caso, se mantiene el statu quo que se podría representar numéricamente como $(3,3)$. Ambos mantienen el mismo grado de oportunidades de ganar el campeonato sin endeudarse.

En la segunda alternativa, (A) decide unilateralmente romper el pacto tácito y opta por realizar un fichaje caro el cual le da serias opciones de ganar el campeonato. El resultado sería entonces, dado que se trata de un juego de suma cero $(10,0)$. Pero también puede darse la situación inversa (tercer escenario): ahora es (B) el que imagina también esa jugada con lo que el resultado posible sería el contrario $(0,10)$.

El cuarto escenario posible es el resultante de que ambos clubes deciden fichar a un jugador pagando una alta suma económica. En este supuesto, ninguno obtiene de manera clara una ventaja deportiva dado que el rival también ha fichado a un gran jugador. Sin embargo, ambos salen perdiendo desde un punto de vista económico ya que ambos se han endeudado, con lo cual su situación podría representarse numéricamente como $(-2,-2) .{ }^{14}$

\begin{tabular}{|l|ll|ll|}
\hline & \multicolumn{3}{|l|}{} \\
\hline & 3 & 3 & 0 & 10 \\
\hline A & 10 & 0 & -2 & -2 \\
\hline
\end{tabular}

Una competición deportiva no es un juego con un único jugador sino con diversidad de jugadores. Y como se acaba de mostrar, los factores que caracterizan a la competición conducen a esa "carrera armamentística» en la que todos salen perdiendo. Como señalan Kuper y Szymanski comentando un estudio sobre el endeudamiento de los clubes españoles entre 1993 y 2004 señalaron:

14 El símil con la guerra armamentística durante la guerra fría y la amenaza del uso de la bomba atómica es evidente. A EE.UU y la uRss les convenía no iniciar la guerra ni la carrera armamentística $(3,3)$, pero ambos podrían verse tentados a eliminar al rival político-económico iniciando un ataque nuclear $(10,0 ; 0,10)$. Pero si ambos rompían el pacto tácito de no aumentar el arsenal armamentístico su situación empeoraba colectivamente $(-2,-2)$. 
«Todos los clubes, independientemente de quien los dirigiese y del lugar que ocuparan en la clasificación de la liga, tendían a perseguir los goles antes que los euros. En cierto sentido, tenían que hacerlo. Si sus rivales gastan todo lo necesario para ganar partidos, usted deberá hacerlo también. Seguramente todo aquel que pusiera la mira en obtener los máximos rendimientos acabaría descendiendo de división, porque no gastaría lo suficiente para fichar a buenos jugadores.Y si el club bajara de categoría, perdería buena parte de sus ingresos. Por tanto, el fútbol se convierte en una suerte de carrera armamentística: todos los clubes gastan demasiado por miedo a sus vecinos».

Así por ejemplo, entre 1994 y 2004 los ingresos de los clubes se multiplicaron por 14 , de 4,3 millones de euros a 59. Ahora bien, «el porcentaje de los ingresos que los clubes invirtieron en los sueldos de los futbolistas no descendió mucho durante ese período: un $62 \% » .{ }^{15}$ En segunda división, la situación fue todavía más grave: el porcentaje fue del 93\%.

Este diseño del mercado de fichajes es, precisamente, el que explicaría la segunda debacle económica del fútbol español. No es solo que los gestores del fútbol español sean malos en sentido técnico, había razones estructurales que les conducían a tomar medidas que a la larga serían ineficientes.

$\mathrm{Y}$ un instrumento como los FI destinados a facilitar la contratación de fichajes no hace sino fomentar la «carrera armamentística». En este sentido, si ahora recordamos la frase del dirigente atlético concluiremos que es cierto que los FI han cumplido su finalidad... pero solo respecto del Atlético de Madrid. El resto de clubes que han participado en la competición no han logrado la victoria deportiva y además habrán empeorado su estado de cuentas. Es decir, que colectivamente la situación es peor. ${ }^{16}$

Ese esquema es el que permite explicar, al menos parcialmente la actual situación delicada en la estructura financiera de los clubes caracterizada por «el excesivo aumento de gastos, que no se ha visto compensado con un incremento equitativo de los ingresos y que ha llevado a los clubes a su actual descapitalización» (De Dompablo, p. 112). Y si ponemos la atención en cuál es la porción principal de los gastos de los clubes de fútbol profesionales, la respuesta es obviamente: fichas, sueldos y salarios de los futbolistas. Según el informe del CSD: "Añadiendo la amortización de los derechos de adquisición de jugadores (imputación diferida a los gastos del ejercicio del coste para el club del transfer del jugador) el porcentaje de

15 Señalan Ascari-Gagnepain «Paradoxically, the main cause of the financial crisis in these clubs (europeans, specially spanish) has been the increasing amount of income entering the game, from television and other sources» (Ascari-Gagnepain, p. 487). Entre esas otras fuentes, está obviamente, la financiación a través de FI.

16 En la práctica, todos los clubes excepto el Real Madrid, el FC Barcelona,Athletic de Bilbao y Osasuna, han recurrido a fondos de inversión, los cuales en 2013 aportaron más de 100 millones de euros a dichos equipos (De Dompablo, 113). 
los gastos asociados al personal se eleva hasta casi el $70 \%$ de los gastos de la competición». ${ }^{17}$

Y si esto así, parece instrumentalmente contradictorio reclamar la existencia de los Fi cuyo objetivo es alentar a los clubes a fichar por encima de sus posibilidades económicas reales y a la vez reclamar a los clubes políticas económicas restrictivas de gastos salariales. En este sentido, habría una marcada contradicción con el Reglamento de Control Económico cuyo principal objetivo es promover la solvencia de los clubes, así como con el Fair Play Financiero.

El primero busca:

a) Mejorar la capacidad económica y financiera de los clubes, incrementando su transparencia y credibilidad.

b) Otorgar la debida importancia a la protección de los acreedores, garantizando que los clubes salden puntualmente sus deudas con los jugadores, Seguridad Social,Agencia Tributaria y el resto de clubes.

c) Fomentar una mayor disciplina y racionalidad en las finanzas de los clubes de fútbol.

d) Alentar a los clubes a operar en base a sus propias capacidades de ingresos.

e) Fomentar el gasto responsable en beneficio del fútbol a largo plazo.

f) Proteger la viabilidad y sostenibilidad a largo plazo de las Ligas y los clubes.

El Fair Play Financiero persigue:

a) Aumentar la capacidad económica y financiera de los clubs, fomentando la búsqueda y generación de nuevas fuentes de riqueza, como por ejemplo

(i) la eficiente explotación de los derechos comerciales y

(ii) la aproximación a mercados de derechos internacionales, como el asiático.

b) Introducir una mayor disciplina y racionalidad en las finanzas de los clubs, con el propósito de aumentar su transparencia y credibilidad.

17 http://www.csd.gob.es/csd/estaticos/noticias/balance-economico-futbol-primeraysegunda2013.pdf Pág. 21. Última visita: 11/6/2015 
c) Garantizar que los clubs resuelvan sus pasivos de forma oportuna, especialmente sus responsabilidades frente a otros clubs, jugadores y autoridades sociales/tributarias.

d) Animar a los clubs a competir con sus propios ingresos («Punto de Equilibrio» $\mathrm{o}$ «Break-Even»), para evitar el concepto de «doping financiero» y minimizar el riesgo de desaparición de los clubs europeos.

e) Reducir la presión sobre los salarios y traspasos de jugadores, con el fin de limitar el efecto inflacionario. ${ }^{18}$

f) Proteger a la viabilidad del fútbol europeo; un gran número de clubs europeos han reportado pérdidas en los últimos años de forma repetida, a pesar de que el fútbol no se ha visto afectado por la recesión económica.

Como resultado de la aplicación del Fair Play Financiero entre 2011 y 2012, las pérdidas de los clubs se están estabilizando, destacándose la reducción de la deuda de traspasos e impagos de 57,1 a 18,3 millones de euros (Rodrigo, 6). Y es que precisamente, estos instrumentos están pensados y aplicados con el mismo propósito que en la lógica económica las leyes de defensa de la competencia, y que no es otro que convertir un juego de suma cero en uno del tipo ganar-ganar. Y para ello, las medidas de Fair Play Financiero pretenden cambiar los incentivos de los clubes de fútbol. Por eso, los FI son contradictorios con esos objetivos porque afianzan la pretensión en principio legítima, pero a la larga autodestructiva de los clubes.

\section{CONCLUSIONES}

En este trabajo hemos tratado de mostrar que los fondos de inversión, en tanto que instrumentos financieros a disposición de los clubes para financiar los fichajes de jugadores que de otra manera inalcanzables pueden ser considerados como un factor positivo. Sin embargo, no se puede esconder que bajo esa apariencia de herramienta jurídico-económica dinamizadora del mercado de fichajes existen amenazas serias que pueden desmenuzarse en cuatro apartados: 1) a los derechos laborales de los futbolistas en tanto que trabajadores; 2) a la integridad de la competición, ya que los fondos pueden interferir en el normal desarrollo de aquella influyendo en el rendimiento de los jugadores y de los clubes; 3) en la lealtad de los aficionados

18 A nivel europeo, entre 2007 y 2011 los sueldos y costes asociados habían aumentado un 38\% entre, superando el crecimiento del $24 \%$ de los ingresos en ese periodo. 
respecto de su club; 4) en la propia salud económica de los clubes, pues a largo plazo pueden contribuir a un progresivo endeudamiento.

Nuestra atención se ha centrado en las dos últimas amenazas. Respecto de la primera hemos tratado de señalar los FI contribuyen a minar el entramado de relaciones coherentes entre club, jugadores y aficionados, que son las que asientan la lealtad de un aficionado a su club. En la medida que un FI (o varios) puede poseer los derechos económicos de uno o varios jugadores de un mismo club, se desconoce, por quién y para quién juega el futbolista. Por otro lado, los FI son entidades ubicuas que carecen de vinculación territorial, histórica y anímica con el club al que financian. Y si esto llega a ocurrir las probabilidades de que los aficionados se desvinculen del club son altas.

\section{BIBLIOGRAFÍA}

Ascari, G. y Gagnepain, P. (2007): «Evaluating Rent Dissipation in the Spanish Football Industry", Journal of Sports Economics, 8: 468.

Avezuela, J. (2015): «La posición de los fondos de inversión desde la perspectiva de negocio de los mismos. Su irrupción en la actividad deportiva», en Palomar, A., Cazorla, L., De Dompablo, S., Avezuela, J. (2015). Los fondos de inversión y la actividad deportiva, Cizur Menor. Thomson Reuters-Aranzadi.

Cazorla, L. (2015): «La actuación de los fondos de inversión en el fútbol español: una aproximación desde una perspectiva jurídico-mercantil», en Palomar, A., Cazorla, L., De Dompablo, S., Avezuela, J. (2015). Los fondos de inversión y la actividad deportiva, Cizur Menor. Thomson ReutersAranzadi.

CAZORLA, L. (2013): «SAD y crisis financiera del deporte profesional: ¿solución o problema?». http://luiscazorla.com/2013/11/sad-y-crisis-financiera-deldeporte-profesional-solucion-o-problema/

De Dompablo, S. (2015): «La perspectiva económica de los fondos de inversión en el deporte» en Palomar,A., Cazorla, L., De Dompablo, S., Avezuela, J. (2015). Los fondos de inversión y la actividad deportiva, Cizur Menor.Thomson Reuters-Aranzadi.

GaRcí́ CABA, M. M. (2013): «El fútbol profesional ante los fondos de inversión: Hacia una necesaria regulación». Revista Aranzadi de derecho de deporte y entretenimiento n.40.

KuPer, S. y SZYMANSKi (2010): El fútbol es así, Barcelona, Urano. 
Molina, D. (2015): «La relación entre el fútbol como actividad mercantil y como fenómeno pasional: una breve reflexión sobre sus implicaciones jurídicas», Revista Española de Derecho Deportivo, 36, 2015.

Otero Lastres, J. M. (2014): «Algunos problemas de los clubes de fútbol» en AAVV (2014). Liber Amicorum, Juan Luis Iglesias, Madrid, Thomson Reuters Civitas.

Palomar, A., Cazorla, L., De Dompablo, S., Avezuela, J. (2015): los fondos de inversión y la actividad deportiva, Cizur Menor. Thomson ReutersAranzadi.

Palomar, A. (2015): «Los derechos susceptibles de revestir interés para los fondos de inversión desde una perspectiva deportiva» en Palomar,A.-Cazorla, L. - De Dompablo, S.-Avezuela, J. (2015). Los fondos de inversión y la actividad deportiva, Cizur Menor.Thomson Reuters-Aranzadi.

Rodrigo, V. (2013): «Fair Play Financiero y Caso Striani», Iusport. Disponible en http://iusport.com/not/990/fair-play-financiero-y-caso-striani/ Última visita: $11 / 6 / 2015$

SANDEL, M. (2008): Deporte e identidad cívica en Filosofía política. Ensayos sobre moral en política, Barcelona, Marbot ediciones.

\section{NORMATIVA}

UEFA Club Licensing and Financial Fair Play Regulations http://www.uefa.com/ MultimediaFiles/Download/Tech/uefaorg/General/01/50/09/12/1500912_ DOWNLOAD.pdf Última visita: 11/6/2015

Reglamento de control económico de los Clubes y Sociedades Anónimas Deportivas afiliados a la Liga Nacional de Fútbol Profesional. http://files. lfp.es/201409/15120514nuevo-libro-x--versi--n-aprobada-el-21-de-mayo2014-.pdf Última visita: 11/6/2015 